\title{
Playing it Safe: Approaching Science Safety Awareness through Computer Game-Based Training
}

\author{
Iwona Miliszewska and Ewa M. Sztendur \\ Victoria University, Melbourne, Victoria, Australia
}

Iwona.Miliszewska@vu.edu.au Ewa.Sztendur@vu.edu.au

\begin{abstract}
Safety is a critical component of any workplace. Within the Science area it is especially important to train students in appropriate safe work practices, as they might be exposed to toxic chemicals, hazardous biological material, and potentially dangerous instrumentation. However, it is often difficult to develop the essential safety awareness, knowledge, and skills in students. This article reports on an innovative approach to lab safety training: the development of an interactive computer game to serve as a lab safety tutorial for science students. The article presents the rationale for the development of the game, outlines its features, and discusses the potential application of the game across the educational sector.
\end{abstract}

Keywords: computer game, computer-based training, safety awareness, science laboratory, science safety.

\section{Introduction}

Safety is of paramount importance in science and science education - and this is the reason why appropriate safety skills need to be developed in students and safety procedures observed in laboratory classes. Closely associated with this, is the need for appropriate behavior from students, and the need for them to be careful for their own safety, the safety of others and of the environment. Learners must be able to be trusted to use potentially dangerous and possibly expensive facilities and equipment sensibly. What are the current approaches to developing the necessary safety awareness and skills in science students? What are the challenges?

Alaimo, Langenhan, Tanner, and Ferrenberg (2010) reported that student lab practices and attitudes were lacking when traditional approaches to safety training were followed; these traditional methods include: introductory presentations to lab safety rules in the first class, weekly presentations by instructors of experiment specific safety concerns, and brief safety quizzes based on assigned reading. The authors noted that students were "bored by the litany of lab safety rules and

Material published as part of this publication, either on-line or in print, is copyrighted by the Informing Science Institute. Permission to make digital or paper copy of part or all of these works for personal or classroom use is granted without fee provided that the copies are not made or distributed for profit or commercial advantage AND that copies 1) bear this notice in full and 2) give the full citation on the first page. It is permissible to abstract these works so long as credit is given. To copy in all other cases or to republish or to post on a server or to redistribute to lists requires specific permission and payment of a fee. Contact Publisher@InformingScience.org to request redistribution permission. brief pre-lab safety notes" (Alaimo et al., p. 856) delivered through traditional methods. Consequently, while students followed the rules regarding the use of personal protective equipment on the one hand, they often removed goggles in the lab, or wore gloves outside of the lab. The current generation of students, the 'digital natives', have grown up playing computer games and using the Internet (Oblinger \& Oblinger, 2005; 
Prensky, 2001). Thus, it may be more of a challenge to gain and keep their attention by just using the traditional methods of safety training. According to Fivvizani (2005), a survey of safety professionals found that boredom was the greatest obstacle to effective training.

Many non-traditional and activity-based approaches have been tried at universities and reported to alleviate lab safety concerns; these activities include safety games (Christoff \& Eves, 2008; Gublo, 2003; Wood-Black, 2000), puzzles (Helser, 1999), cartoons (Di Raddo, 2006), videos (Matson, Fitzgerald \& Lin, 2007; Stepenuck, 2002), skill-building modules (Wright, 2005), peerled guided inquiry (Lewis \& Lewis, 2005), writing-intensive multimedia projects (Van Ryswyk, 2005), and safety teams (Alaimo et al., 2010). Approaches to safety training aim to respond to gaps in knowledge (proactive approach), to target high-risk groups or areas (reactive approach), and to adjust perception of risk (Borys, 2009; Vecchio-Sadus, 2007). However, Hill (2006) points out that one of the biggest challenges of better educating students in safety is to teach them to "understand and recognize hazards" rather than just to follow safety rules (Hill, 2006, p. 18).

This article reports on an innovative approach to addressing the issue of lab safety awareness among sciene students: the development of an interactive computer game to serve as a lab safety tutorial. The article presents the rationale for the development of the game, outlines its features, and discusses the potential application of the game across the educational sector.

\section{Science Safety at Victoria University}

\section{The Science Degree}

The Bachelor of Science degree at Victoria University offers specializations in three science disciplines: Biotechnology, Chemistry, and Ecology and Environmental Management; students can choose to specialize in one or two of these science disciplines. This is a three year degree with a common first year and a choice of sub-specializations in the latter two years. The degree is industry focused, offers an intensive hands-on laboratory experience, provides opportunities for industry projects and placements and, overall, prepares students for careers in the science profession. Those students with scientific research in mind can progress into Honors and postgraduate studies.

The degree aims to produce graduates that are 'work ready' by combining an extensive laboratory program with training on state-of-the-art equipment along with an industry placement program. The Chemistry specialization, for example, combines studies in analytical, forensic and organic chemistry to develop measurement and investigative skills that are highly sought after by industry. The laboratory program is designed to give our chemistry graduates a genuine head start into the work force. After completing second year, students have the opportunity to work in one of over twenty chemical industries as part of their studies.

At present, the safety training in the Science Degree includes a safety briefing at the beginning of a semester, a video (also shown at the beginning of each semester), occupational health and safety (OHS) briefing at the beginning of each laboratory session, and risk assessment for each laboratory session.

\section{Current Level of Safety Awareness}

Anecdotal evidence provided by the science professors suggested that the current approaches to safety training have had a limited impact on student safety awareness. The professors identified students' 'false sense of security' as the most persisting problem. One of the professors described the problem as follows: "Students feel that, as long as they have their lab coat, safety goggles, and gloves on, they are O.K. Consequently, [with their gloves on] they will adjust their hair, open doors, take notes...; they will carry around open beakers...". 
To determine the current level of student awareness with respect to laboratory safety, a trial survey was administered to first-year science students in the second semester of their degree program; the survey was administered twice: first at the beginning of the semester, and then at the end of the semester. Of the 75 students enrolled, 49 completed the pre-survey (65\% response rate), and 36 completed the post-survey ( $48 \%$ response rate); of all the participating students, 19 participated in both surveys. The survey consisted of 16 multiple-choice questions covering essential science safety issues including personal protective equipment, handling of chemicals and biological matter, handling of equipment, emergency procedures, fire control, and management of hazardous waste. The pre-survey also asked if and where the students had studied laboratory safety rules.

Over $54 \%$ of the students claimed not to have studied laboratory safety rules before entering the science degree. Other students indicated that they studied safety rules either in secondary school or while obtaining other post-secondary qualifications such as Certificate in Science or Foundation Studies.

Overall, students answered the majority of survey questions correctly in both the pre- and postsurveys, with the rate of correct responses slightly higher in the post- survey (Table 1). However, the survey revealed three important safety issues where student awareness was alarmingly lacking. In the pre-survey, only $47 \%$ of respondents provided correct answer to question 5 , related to flammable materials. Questions related to washing procedures (question 7) and the smelling of liquids (question 4) were answered only marginally better (51\% and 61\% respectively). An improvement in responses to those questions was recorded in the post-survey; however, the highest percentage of correct responses was still only at $70 \%$. The poor responses to the three questions are a cause of concern especially as the participating students had completed two semesters of chemistry and biology classes (including extensive laboratory component) before completing the post-survey.

Table 1: Percentage of correct answers in pre- and post-surveys.

\begin{tabular}{|c|c|c|}
\hline Safety issue tested & $\begin{array}{l}\text { Pre-survey } \\
(\mathrm{N}=49)\end{array}$ & $\begin{array}{l}\text { Post-survey } \\
(\mathrm{N}=36)\end{array}$ \\
\hline 1. correct waste disposal & 98 & 97 \\
\hline 2. correct sharps disposal & 86 & 91 \\
\hline 3 use of latex gloves & 90 & 88 \\
\hline 4 smelling of liquids & 61 & 70 \\
\hline 5 flammable materials & 47 & 50 \\
\hline 6 use laminar flow cupboards & 100 & 97 \\
\hline 7 washing procedures & 51 & 65 \\
\hline 8 personal protective equipment worn & 98 & 100 \\
\hline 9 labeling & 96 & 100 \\
\hline 10 food or drink in lab & 96 & 97 \\
\hline 11 appropriate attire & 100 & 100 \\
\hline 12 evacuation procedures & 96 & 97 \\
\hline 13 emergency procedures & 96 & 94 \\
\hline 14 reporting of hazards & 96 & 100 \\
\hline 15 clean up of spills & 96 & 100 \\
\hline 16 lab experiments (good practice) & 82 & 85 \\
\hline
\end{tabular}


In the post-survey students were also asked to rank, in order of usefulness (using numbers 1 to 4 , with " 1 " indicating "very useful"), the various ways in which they learnt about occupational health and safety throughout the study year. The options presented for ranking included: 'Safety briefing at the beginning of the semester', 'OHS briefing at the beginning of each laboratory session', and 'Risk assessment for each laboratory session'. The majority of students found each of the options either very useful (Rank 1) or useful (Rank 2), as illustrated in Table 2. In addition, students were asked to indicate the potential usefulness of an interactive computer game for lab safety training; over half of the students were of the view that a computer game would be very useful or useful. This finding suggests that students appreciate a multi-pronged approach to lab safety training.

Table 2: Student ranking of the usefulness of current means of lab safety training.

\begin{tabular}{|l|r|r|r|r|}
\cline { 2 - 5 } \multicolumn{1}{c|}{} & $\begin{array}{c}\text { Rank 1 } \\
\mathbf{( \% )}\end{array}$ & $\begin{array}{c}\text { Rank 2 } \\
\mathbf{( \% )}\end{array}$ & $\begin{array}{c}\text { Rank 3 } \\
\mathbf{( \% )}\end{array}$ & $\begin{array}{c}\text { Rank 4 } \\
\mathbf{( \% )}\end{array}$ \\
\hline Safety briefing at the beginning of the semester & 38 & 24 & 38 & 0 \\
\hline OHS briefing at the beginning of each laboratory session & 24 & 48 & 24 & 4 \\
\hline Risk assessment for each laboratory session & 31 & 28 & 38 & 3 \\
\hline Interactive computer game * & 21 & 35 & 29 & 15 \\
\hline
\end{tabular}

* - option under consideration (not part of the current lab safety training)

\section{Science Safety Game}

Given the importance of training students in appropriate laboratory safety practices on the one hand, and the difficulty of achieving the desired level of safety awareness among students through the existing approaches to safety training, it was decided that an innovative alternative should be considered. The objective was to introduce into the safety training framework a component that would develop the necessary awareness in students in an engaging way. Thus, the idea to develop an interactive computer game, Science Safety Game, to serve as a science safety tutorial was born.

\section{Addressing the 'False Sense of Safety'}

Research points to the increasing body of knowledge that suggests that attempts aimed to protect, have the opposite effect - making individuals less safe and, crucially, less able to manage risk (Berg, 2010). Thus, many of well-meaning attempts to make individuals safer are counterproductive, making them more likely to take risks, and less likely to think about the consequences. For example, Walker (2007) reported that drivers come closer to cyclists on the road if the cyclists are wearing bike helmets, thus acting more dangerously on the assumption that the rider is safe. Other examples include people who fail to protect their property when it is insured, or bushwalkers who venture further into the wilderness, if they believe search and rescue teams will be there to help them (Berg, 2010). Similarly, there are the science students, who feel invincible once they wear lab coats, safety goggles, and gloves. Stepenuck (2002) refers to this phenomenon as the "YMIS" ("Young Male Invincibility Syndrome") and points out the difficulty of reaching into the heads of students suffering from it. Green and Hill (2002) agree that young males are less likely to observe safety procedures and more likely to engage in excessive risk-taking.

There are solutions. Berg (2010) reports that, some towns in Europe are removing traffic lights, stop signs, and other road markings, in a bold attempt to revolutionize traffic management. Consequently, drivers enter intersections more slowly and more attentively and, rather than focusing their attention on signs, they make eye contact with other drivers, and negotiate. Accidents in 
these towns have dramatically declined. A similar type of solution might help address the issue of science lab safety, albeit in a controlled way. Computer games have the potential to simulate dangerous science laboratory situations and help users learn about managing danger without putting them in real harm's way.

\section{Rationale}

The key rationale for the development of the Game was to provide safety training that alters the attitude of the science student so that a dangerous 'situation' encountered while playing the game does not occur in a real laboratory in the first place. The choice of a computer game as a medium for the safety training was guided by the desire to best connect with the intended users (undergraduate university students). Research shows that students tend to remember $90 \%$ of what they learn if they do the job themselves, even if it is only a simulation and, on average, students (up to the age of 20) spend nearly an hour a day playing computer/video games (Summit on Educational Games, 2006). In addition, the game format has many advantages over the old-fashioned methods of teaching. Games can break down complex tasks, guiding players through a series of small steps; they can be adapted to the individual pace of the learner and give immediate and continuous feedback; game-based tasks may require students to formulate hypotheses and experiment; and, learners can control their navigation of the games. Each of these characteristics has been linked with better learning outcomes (Gee, 2007; Mayo, 2009; Whitton, 2009). Consequently, computer games have the potential to serve as a good vehicle for communicating science safety to students. Effective communication mechanisms are essential to engage students in safety activities, to gain their cooperation, and to maintain a positive safety culture. The way of communicating safety will influence students' understanding of, and participation in, the safety process, and the communication language will often determine whether students accept or reject the process (Vecchio-Sadus, 2007).

Thus, the objective of the Game was to combine educational content with gaming art/programming to create an interactive, engaging, educational computer-based training with video game-type qualities and features. The goal of incorporating the Game in OHS training of science students was to make them safer by "exposing" them to risks (in a simulated environment). Consequently, the overall aim of the training was to:

- impart essential and "serious" OHS knowledge and skills in a way that is creative and fun, so students can practice safely and remember better;

- teach students how to be responsible and proceed with caution in a science lab before they start practising science in a real laboratory;

- make use of students' familiarity with, and fondness of, computer games (many young people are consumers of games on home computers that involve them in exciting problem-solving activities), and develop their awareness of OHS issues through game-based exploration of OHS events and consequences;

- engage students and make them active agents in their own learning through the combination of the engaging factors of 3D games and the benefits of role-playing for enhanced learning; in the Game, the students play the role of laboratory staff who need to make safety-based choices relating to handling chemicals and biohazards, interact with staff and supervisors, operate instruments, and carry out tasks (M.O'Rourke, personal communication, 8 June 2009, as cited in O'Rourke, Papasimeon \& Custance, 2008);

- incorporate elements of competition to the learning experience; the goal of the Game is to successfully perform a day's work safely and without injuring themselves or their fellow 
laboratory personnel, or destroying equipment (M.O’Rourke, personal communication, 8 June 2009, as cited in O'Rourke, Papasimeon \& Custance, 2008); and,

- include a variety of assessment tasks to reinforce the acquired OHS knowledge and skills.

\section{Design and Development}

The Game was designed to provide learning opportunities and a motivational context in which to learn through the combination of an immersive three-dimensional (3D) virtual environment and role-playing techniques; according to the literature, the 3D "full immersion" games help students develop critical thinking skills (Barab et al., 2009). The design facilitates student engagement (an essential contributor to learning effectiveness) through the combination of six factors: interactivity, narrative, competition, game-play, dramatic effects, and playability. While the Game covers a wide spectrum of safety issues relevant to university science studies, the Game's laboratory is called "National Forensics" (Figure 1; the screen shots presented in Figures 1 and 3-5, have been created by game developers N.Powell, L.Hawkes, C.Rubino, and C.Barton.), and the "action" of the Game imitates a scenario from a crime scene investigation (similar to those of popular TV shows), as illustrated in Figure 2 (the scenario has been created by A.Smallridge, M.O’Rourke, and J.Custance).

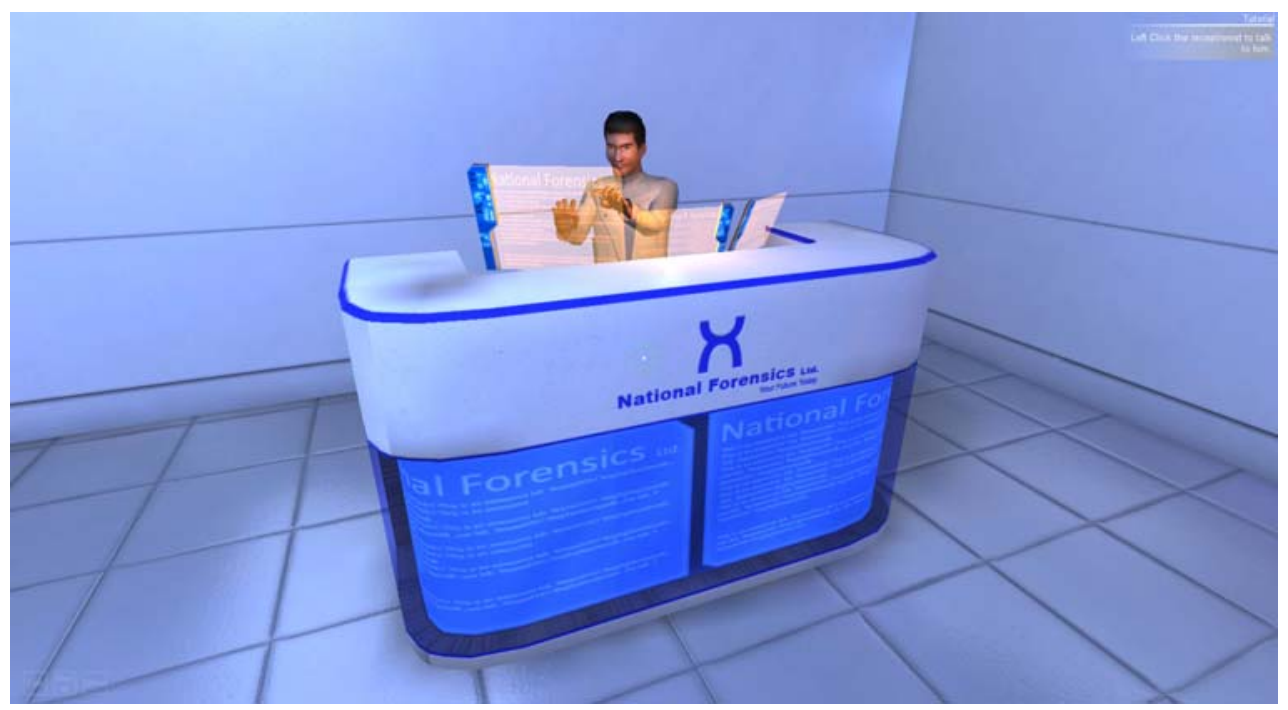

Figure 1: The Game's laboratory setting.

Opening cinematic:

- Location round the corner from lab

- $\quad$ Night of the murder

- $\quad$ Dark alley, rainy night, figure drops to the ground screaming.

- $\quad$ Figure lying on ground under raincoat, pool of blood ...

Next morning:

- Chalk marks in body shape; light bulbs flashing.

- Policemen milling around; lab building "National Forensics" in the background

- Policeman approaches to close-up and addresses the user as a lab technician sent over to the scene ...

The task:

- Use the lab results to eliminate suspects (4 suspect profiles provided)

Figure 2: The scenario. 
The above scenario involves training in the following laboratory safety principles:

- Potential biological, chemical, and physical hazards

- Routes of exposure

- Safety reference materials

- Emergency preparedness and response basics

- Measures of protection

The activities involved in the training include: bacterial analysis (all work to be done in laminar flow cupboard; sample potentially pathogenic); illicit drug analysis (all work to be done in fume cupboard); and, heavy metal poison analysis.

The focus of the design phase of the Game development was to invest maximum effort in scripting, environment, and audio, as these were seen as the most important aspects of creating desired understandings. Some specific details such as signage and safety instructions were also regarded as important to achieving the learning objectives (Figure 3); other details such as realistic animation were viewed as less critical.

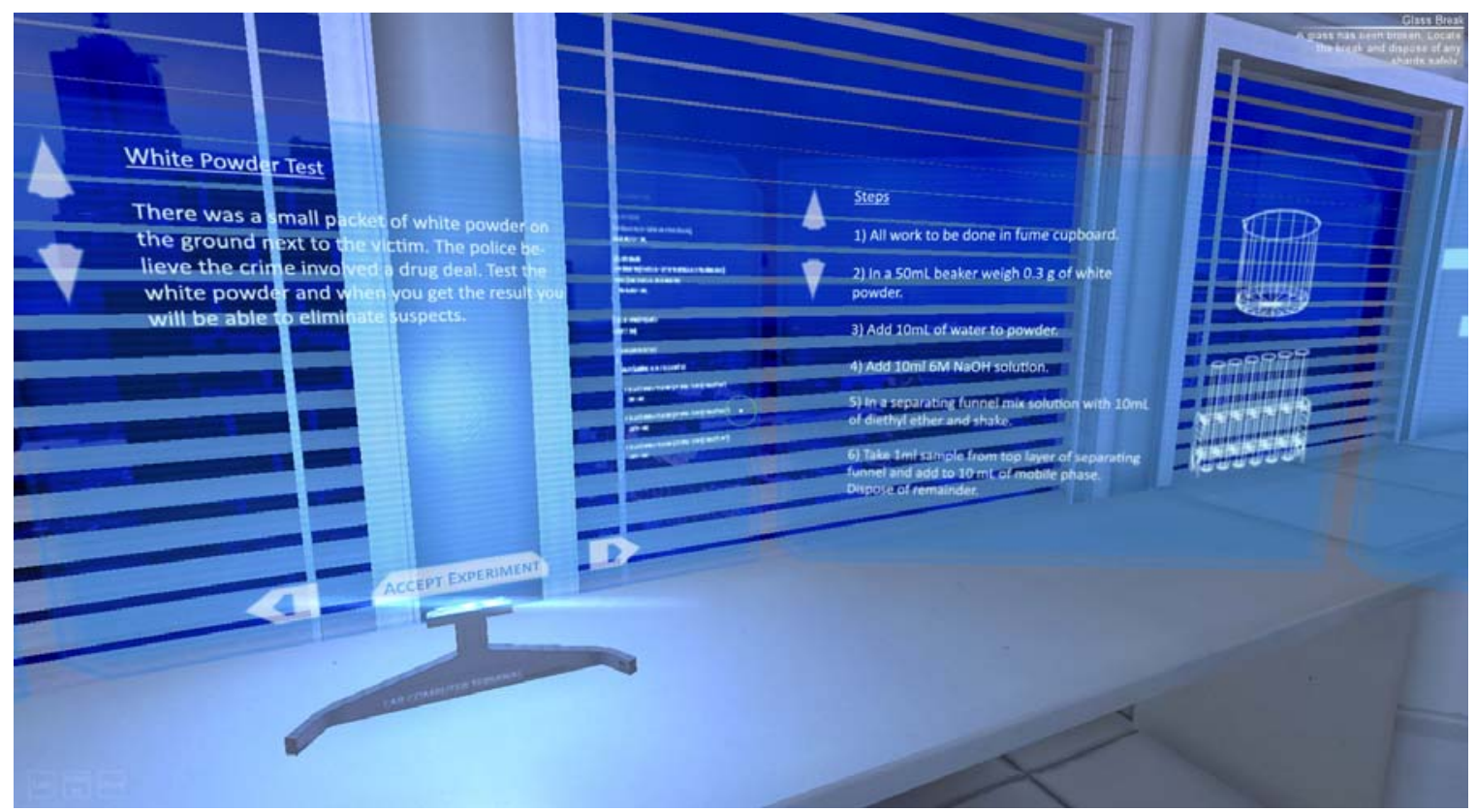

Figure 3: Example of task and safety instructions.

The focus of the development phase was to use objects that provided enough realism to communicate key messages and, to use audio information, as well as visual cues, to communicate key information; this was regarded as more effective and direct way to present certain messages, especially alerts, with maximum clarity (Figure 4, Figure 5). 


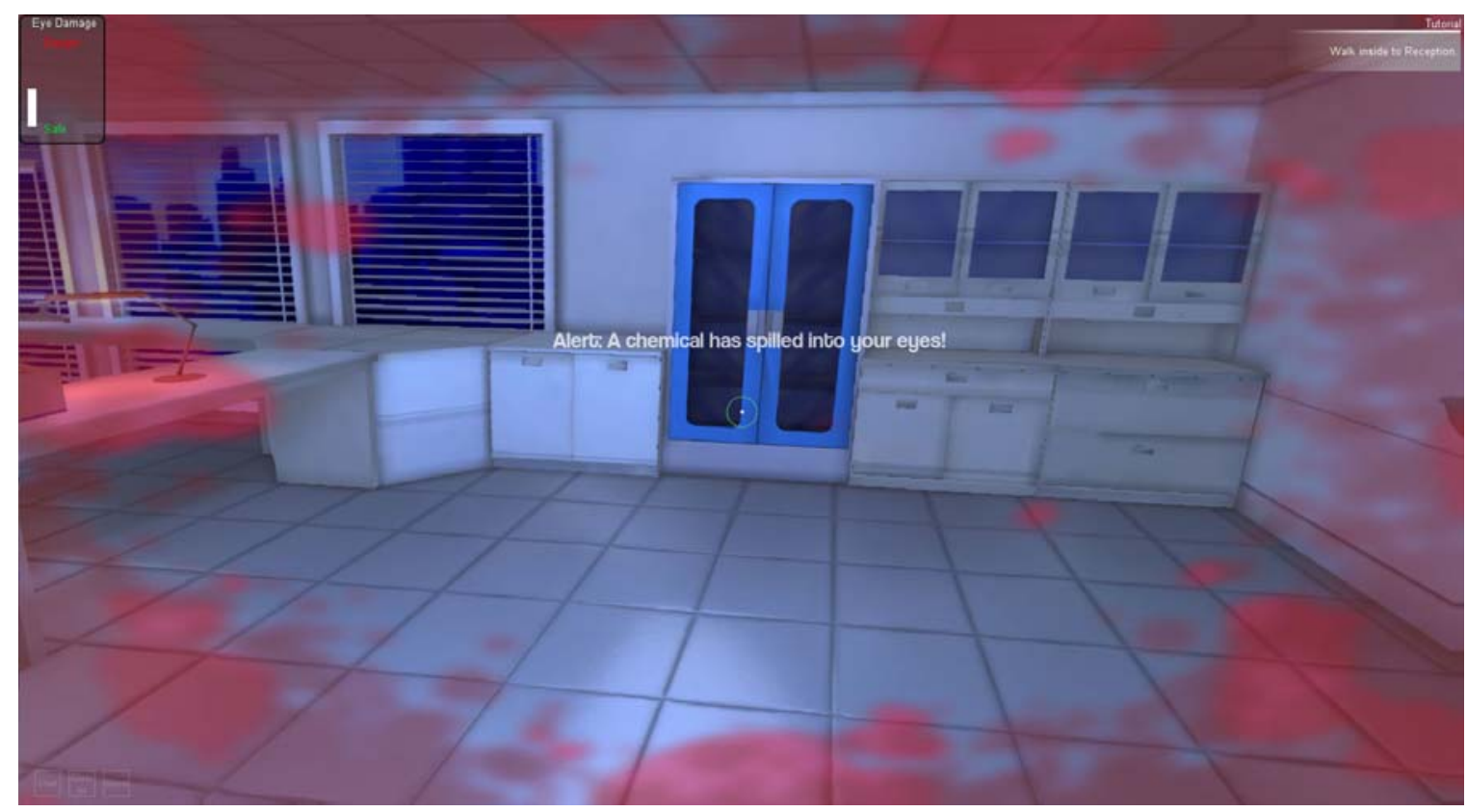

Figure 4: Example of an alert.

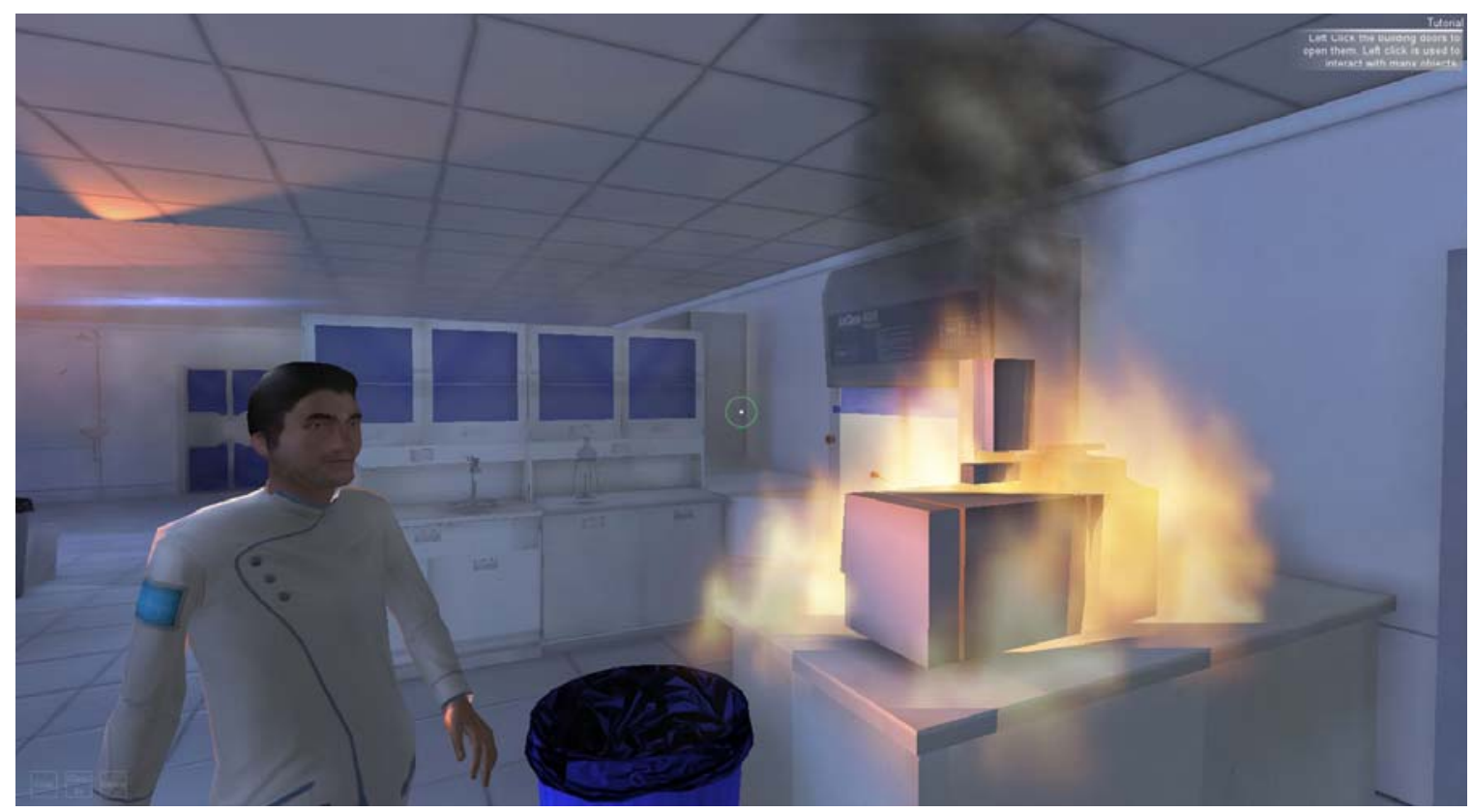

Figure 5: Example of a visual effect (fire in the lab).

The Game was designed to give players instructions and cues to help them perform the required tasks; it also gives a player some time (measured by a timer) to take the necessary safety steps (for example, put on safety goggles). However, if a player ultimately fails to observe lab safety rules, the game fails and the player needs to start again. Thus, playing the game forces students to learn about the material. Squire (2006) identified 'failure' in educational games as a critical precondition for learning. Failure is valuable in gaming; it makes students confront gaps or flaws in their current understandings through cycles of recursive play (Squire, 2006). Failure is also valuable in learning. Students can be told countless times, but making the mistake and the proper ad- 
justment creates deeper connections with the content than simply trying to remember the answer. According to Hein (2010), game players learn as much from victory as they do from failure.

The evaluation of the Game will be carried out in semester 1 of 2011; it will gauge the impact of the Game on raising the level of lab safety awareness among students. While initially the Game was intended for students in the Science Degree, it has attracted interest from teaching staff in other science programs. Consequently, the evaluation will be carried out in three different educational environments and involve:

- Higher Education students from the Specialist Science Degree, Education, as well as Foundation Studies.

- Vocational Education students from Certificate III \& IV including:

- $\quad$ Cert III Laboratory Skills, Cert IV Science

- $\quad$ Cert IV Laboratory Technology

- $\quad$ Cert III Companion Animal Studies

- $\quad$ Cert IV Veterinary Nursing

- Secondary school students participating in Victoria University's annual chemistry and biology classes.

\section{Conclusions}

Appropriate science safety culture can and should be developed in the university, and science students should be taught the consequences of neglecting safety. This is especially important, as science graduates are likely to be employed in a variety of roles within the biotechnical, chemical and related industries and, if the university science education is to be vocationally relevant, then OHS needs to be integrated and promoted in the science curriculum. Given the advances in educational technologies, universities could redesign their instructional OHS practices and formal learning environments to take advantage of technology-enabled exploration, interactivity, and collaboration encouraged by digital games and simulations.

This article outlined the development of an interactive computer game, Science Safety Game, designed to be used as a lab safety tutorial for science students. The game provides the advantage of a 3D interface with near real-world representation for applying learning-by-doing and casebased reasoning approaches. The topics covered in the Game include chemical and biological hazards, electrical, emergency preparedness, fire control, handling glassware, hazardous material storage, hazardous waste management, personal protective equipment, and ventilation. The Game is planned to be a key component of OHS training in science among the tri-sectoral stakeholders from 2011 onwards; they include students in higher education, vocational post-secondary education, as well as secondary school students. In addition, the universal nature of the Game has the potential to attract interest from other universities, technical and further education colleges, and secondary schools.

Preliminary responses from stakeholders (a sample of science professors and students) confirmed the Game's usefulness in setting the scene and communicating the key information. However, an extensive evaluation will follow to determine if the game will succeed to create the emotional engagement necessary to inspire behavioral change.

\section{Acknowledgements}

The authors would like to acknowledge contributions to the Science Safety Game project from: project team members A/Prof A.Smallridge and M.O’Rourke; game script writer J.Custance; game developers N.Powell, L.Hawkes, C.Rubino, and C.Barton; and, member of the project Advisory Group A.Taylor. 
The project has been funded by a Teaching and Learning Support grant from Victoria University as well as contributions from the Faculty of Workforce Development and the School of Engineering and Science at Victoria University.

\section{References}

Alaimo, P. J., Langenhan, J. M., Tanner, M. J., \& Ferrenbeg, S. M. (2010). Safety teams: An approach to engage students in laboratory safety. Journal of Chemical Education, 87 (8), 856-861.

Barab, S.A., Scott, B., Siyahhan, S., Goldstone, R., Ingram-Goble, A., Zuiker, S., \& Warren, S. (2009). Transformational play as a curricular scaffold: Using videogames to support science education. Journal of Science Education and Technology, 18, 305-320.

Berg, C. (2010). Helicopter governments promote an illusion of safety. The Age. Retrieved October 24, 2010 from http://www.theage.com.au/opinion/politics/helicopter-governments-promote-an-illusion-ofsafety-20101023-16yhe.html

Borys, D. (2009). Exploring risk-awareness as a cultural approach to safety: Exposing the gap between work as imagined and work as actually performed. Safety Science, 13 (2), 1-11. Retrieved September 5, 2010 from http://ssmon.chb.kth.se/vol13/issue2/3_Borys.pdf

Christoff, D., \& Eves, G. (2008). Considerations for serious games use in safety culture improvement in the resources industry, in Proceedings of the SimTecT Conference, Melbourne, May 12-15. Retrieved September 3, 2009 from http://www.miskillscentre.com.au/media/102229/111\%20deanna_gary.pdf

Di Radio, P. (2006). Teaching chemistry lab safety through comics. Journal of Chemical Education, 83 (4), 571-573.

Fivizzani, K. P. (2005). The evolution of chemical safety training. Chemical Health and Safety, November/December, 11-15.

Gee, P. G. (2007). Good video games + good learning. New York: Peter Lang.

Green, R. J., \& Hill, R. H. Jr. (2002). Safety survival skills - The development of computer based safety training at the Centers for Disease Control and Prevention, in Proceedings of an online Conference on Teaching Safety in High Schools, Colleges, and Universities, September 30-November 21. Retrieved October 10, 2010 from http://www.files.chem.vt.edu/confchem/2002/c/green/green.htm

Gublo, K. I. (2003). A laboratory safety trivia game. Journal of Chemical Education, 80 (4), 425.

Hein, E. (2010). Video games and failure-based learning. GMAT, Knewton. Retrieved October 15, 2010 from http://www.bschooladmissionsformula.com/video-games-and-failure-based-learning/

Hill, R. H. Jr. (2006). The emergence of laboratory safety. Journal of Chemical Health \& Safety, 14 (3), 14-19.

Lewis, S. E., \& Lewis, J. E. (2005). Departing from lectures: An evaluation of a peer-led guided inquiry alternative. Journal of Chemical Education, 82 (1), 135-139.

Matson, M. L., Fitzgerald, J. P., \& Lin, S. (2007). Creating customised, relevant, and engaging laboratory safety videos. Journal of Chemical Education, 84 (10), 1727-1728.

Mayo, M. (2009). Video games: A route to large-scale STEM education? Science, 323 (5910), 79-82. Retrieved October 15, 2010 from http://www.sciencemag.org/content/323/5910/79.full

Oblinger, D., \& Oblinger, J. (2005). Is It Age or IT: First Steps Toward Understanding the Net Generation? in Educating the Net Generation. Retrieved March 4, 2011 from http://www.educause.edu/IsItAgeorIT\%3AFirstStepsTowardUnderstandingtheNetGeneration/6058

O'Rourke, M., Papasimeon, T., \& Custance, J. (2008). Developing a vocational training computer game workplace simulator: The vocational game project, in Proceedings of the Computer Games \& Allied Technology Conference, Singapore, April 28-30. 
Prensky, M. (2001). Digital natives, digital immigrants. Retrieved March 4, 2011 from http://www.marcprensky.com/writing/prensky\%20\%20digital\%20natives,\%20digital\%20immigrants\%20-\%20part1.pdf

Squire, K. D. (2006). From content to context: Video games as designed experiences. Educational Researcher, 35(8), 19-29.

Stepenuck, S. Jr. (2002). Some thoughts on teaching chemical health and safety, in Proceedings of an online Conference on Teaching Safety in High Schools, Colleges, and Universities. Retrieved October 10, 2010 from http://www.files.chem.vt.edu/confchem/2002/c/stepenuck/stepenuck.htm

Summit on Educational Games (2006). Harnessing the power of video games for learning. Report. Federation of American Scientists. Washington DC. Retrieved November 10, 2010 from http://www.fas.org/gamesummit/Resources/Summit\%20on\%20Educational\%20Games.pdf

Van Ryswyk, H. (2005). Writing-intensive multimedia projects in the instrumental methods course. Journal of Chemical Education, 82 (1), 70-72.

Vecchio-Sadus, A. M. (2007). Enhancing safety culture through effective communication. Safety Science Monitor, 11 (3), 1-10. Retrieved September 3, 2010 from http://ssmon.chb.kth.se/vol11/Issue3/2\%20Vecchio.pdf

Walker, I. (2007). Drivers overtaking bicyclists: Objective data on the effects of riding position, helmet use, vehicle type and apparent gender. Accident Analysis and Prevention, 39, 417-425.

Whitton, N. (2009). Learning with digital games: A practical guide to engaging students in higher education. Hoboken: Routledge.

Wood-Black, F. (2000). Laboratory Safety Training. Chemical Health and Safety, November/December, p. 43.

Wright, S. M. (2005). Introducing safety topics using a student-centred approach. Journal of Chemical Education, 82 (10), 1519-1520.

\section{Biography}

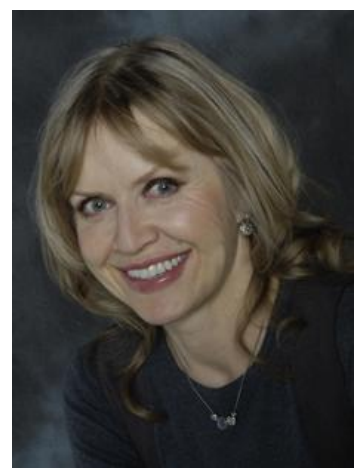

Dr Iwona Miliszewska is Associate Professor in computer science at Victoria University in Melbourne, Australia. She has led and participated in research projects involving transnational education, effective teaching methods, technology-supported learning, and females in ICT, and has published in these areas.

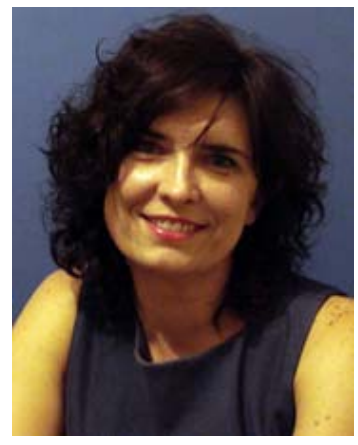

Dr Ewa Sztendur is a Research Fellow in the Office of the Pro ViceChancellor (Students and Learning and Teaching) at Victoria University in Melbourne, Australia. She has a PhD in statistics (experimental design) and has been involved in numerous research projects related to the issues of higher education, including widening participation, gender equity, student use of technology, and student retention and performance. 